\title{
Editorial: A Web-Based Archive of Norms, Stimuli, and Data
}

\author{
JONATHAN VAUGHAN \\ Hamilton College
}

\begin{abstract}
A new public archive of norms, stimuli, data, and source code, www.psychonomic.org/archive, is at the service of researchers and students in experimental psychology. The archive has received contributions from more than 60 researchers. The August and November 2004 issues of Behavior Research Methods, Instruments, \& Computers comprise articles related to the inaugural contents of the archive, which will henceforth accept contributions related to articles published in all Psychonomic Society journals.
\end{abstract}

Print has long been the conventional medium of scientific exchange, from the first issue of the Philosophical Transactions of the Royal Society of London for Improving Natural Knowledge in the mid-17th century to the enormous proliferation of scientific journals in the 20th. As part of this tradition, the Psychonomic Society journals have an illustrious history of sharing scientific information in print. ${ }^{1}$ The Society's commitment to the free exchange of ideas in psychology is further reflected in its liberal copyright policy, which encourages unfettered noncommercial use of published articles. Nevertheless, now that computers and networks are the universal "tools of the trade," information can be stored and shared more efficiently and more accurately in machine-readable form than on paper.

With the August and November 2004 issues of Behavior Research Methods, Instruments, \& Computers, we inaugurate a publicly accessible, Web-based archive of norms, stimuli, and data, which will complement the Society's print journals. The August issue will emphasize norms for textual, verbal, and pictorial materials, while the November

It has been enormously stimulating and rewarding to observe the enthusiastic response to the inauguration of the Web-based archive from researchers in a variety of fields. First thanks go, then, to the authors and coauthors who generously and enthusiastically contributed to the archive, and to the colleagues who reviewed the submitted materials under time pressure, in many instances considering more than one related contribution. The Psychonomic Society Publications Committee, the consulting editors of BRMIC, and the editors of the Psychonomic Society journals offered support and many valuable suggestions. Not all can be mentioned here, but Anne Britt, Richard Carlson, Thomas Carr, Russell M. Church, Jonathon Crystal, Aram Kudurshian, Neil Macmillan, Brian MacWhinney, Robert Proctor, David Rosenbaum, Annie Trapp, John Wixted, and Christopher Wolfe provided especially salient advice. The BRMIC editorial assistants, Colby Fisher and Stephanie Godleski, implemented the contributions to the archive and shared many insights for its design. Finally, publishing a journal in which each printed article must be coordinated with Web content makes the process just a bit more complicated than usual, and I am grateful for the attention and patience of the Psychonomic Society Publications Office and the Society's Web provider, lone-star.net, who have made it possible to smoothly integrate the two. Correspondence may directed to J. Vaughan, Department of Psychology, Hamilton College, Clinton, NY 13323, or to jvaughan@hamilton.edu. issue will highlight the electronic exchange of stimuli, data, and program source code.

Why make norms, stimuli, and data easily accessible in a permanent public archive? The overarching motivation is the facilitation of scientific communication: to enable the most effective and productive critique and extension of previous research. Contemporary scientific reports are, of course, carefully drafted with a hypothetical audience of one colleague, "the reader," firmly in mind. To this end, reports of experiments and observations follow conventional organization ("APA style") and use precise technical expression, so that the reader will be able to critically evaluate, interpret, and potentially replicate the work that is reported.

However, not all information can be included in print. When published information is inadequate, an interested researcher needs more detailed information.

Furthermore, an important dimension of every scholar's responsibilities is education. A readily available repository of norms, stimuli, and data will help provide the raw materials for student projects and inspiration for the design of class projects at all levels of teaching.

Electronic transmission is now the most effective medium for scientific exchange. Information that one researcher might provide another may be so voluminous, or demand such detail and precision, that exchange in print is cumbersome. Electronic exchange, on the other hand, is unencumbered by distance, the volume of the materials, or the cost of printing and distribution on paper. Furthermore, in our age, information often needs to reach an electronic "reader," not a human one. A more extensive report of technical information than can be accommodated in print affords an opportunity for a researcher to reuse someone else's information, transform it, or verify it at a deeper level than would be possible from a print source, or to obtain information that cannot be shared in print.

How to coordinate Web-based archiving with traditional scientific publication? One approach is to archive material independently of conventional print publication. There have been a number of proposals and ongoing experiments in this direction, many of which come under the 
heading of "self-archiving" (see, for instance, Boker \& Crowell, 2004). Well thought out examples include the Timing archive at Brown University (www.brown.edu/Research/Timelab/index.html; see Kirkpatrick \& Church, 2003) for data, and www.cog.brown.edu/ tarr/stimuli. $\mathrm{html}$ for visual stimuli. For the Society's archive, we have elected to incorporate submissions of archiveable materials into the existing process of review for print publication. That is, a journal editor makes the final decision to accept both the article and the material for the Web-based archive, after both have undergone peer review. In this way, we can help ensure that archived materials have undergone, and passed, a rigorous evaluation, and have been adequately documented. The print article provides an opportunity to elaborate on the historical background, characteristics, theoretical implications, methodological issues, and other ramifications of the materials. As Guilhardi and Church (2004) note, while researchers can easily enough share materials on their own Web sites, "an institutional repository such as a university or a scientific society is superior because it provides greater assurance of long-term availability of the data" (p. 662). A centralized archive, under the aegis of a perpetual scientific society, will help ensure the continuity of the resources despite an author's change of institution, the evolution of computer storage formats, or the revision of proprietary file formats.

With these thoughts in mind, the new archive provides a repository for a variety of materials that are of general utility to researchers in the many fields of experimental psychology. Psychonomic Society journal editors and authors may now submit supplemental materials for electronic archiving to complement and enhance the printed publications. Materials unsuitable for print, such as sound files, color or high-resolution photographs, PET or MRI scans, and extensive tables, are all good candidates for the archives, as are data sets or software source code that are best shared in machine-readable form.

What kinds of materials should be archived? In language and cognition research, archiving normative data may be particularly fruitful. Maki, McKinley, and Thompson (2004) have noted that some kinds of linguistic information are relatively straightforward to acquire: word frequency can be counted, co-occurrence of word pairs can be tallied. However, adequately large corpora of words are more difficult to come by for some dependent measures. Maki et al. note that in developing word pairs, because of the challenges of developing large sets of stimuli, the foundation on which the work is based has sometimes been merely intuitive: "There has been a tendency to select first and norm second ... and then for subsequent investigations to rely on those materials" (p. 421). A more coordinated approach is to have a growing repository of useful materials based on multiple contributions.

In studies of perception and memory, to take another example, one laboratory's ability to use stimuli identical to those developed in another helps ensure that the replication and extension of that work does not suffer from some undetected difference in the stimuli. Conversely, access to the original stimuli may reveal defects in them that are impossible to detect from their description in print.

Building on the foundation of a recent NIMH workshop on the topic (Kurtzman, Church, \& Crystal, 2002), Crystal (2004) notes that sharing data facilitates the cumulative progress of science by enabling more informed scrutiny of prior research and the application of diverse methods of analysis to the same set of observed data. A body of data laboriously acquired in one laboratory may serve purposes not envisaged by the original researchers. Testing of alternative models is more rigorous if alternative approaches can be compared using the same data (see the reuse by Heathcote, 2004, of data from Schwarz, 2001, for a particularly salient example).

In developing the archive, I have been reminded (not unexpectedly) that many relevant issues parallel those that affect print publications. First, peer review remains the touchstone for ensuring the quality and clarity of each submission. The journal editor's decision to accept the materials for the archive along with the article rests on the judgment that both will be of utility to researchers and students in psychology. As a rule of thumb, a useful precursor to the submission of materials for the archive is to have demonstrated their utility in previously or simultaneously published peer-reviewed empirical work. Second, where one's archived work incorporates that of others, appropriate permission is required, as it is in print. Finally, it is important to give credit when it is due. Researchers who find archived materials useful in their own work are asked to cite both the relevant article and the archival content, and they are invited to share the products of their work, in turn, with those who provided the materials.

To facilitate perpetual access to the data, whenever possible one version of each archive entry is accessible in open-source format (such as plain text), and the materials are compressed so that all related materials can be downloaded in a single compressed archive file (see Boker \& Crowell, 2004, for further discussion of such issues).

\section{How to Use the Archive}

Browsers will find the archive at www.psychonomic. org/archive. When users first access the archive site, they are asked to confirm agreement with the following terms of use:

\section{Terms of Use}

All rights to materials placed on the Psychonomic Society Web archive remain with the author(s) who have provided them. By making the materials available for archiving, the authors represent that they hold appropriate rights to the materials. If any of the archived materials depend or are based on the work of others, the authors must obtain prior permission from the originators to use the materials, and acknowledge and cite the appropriate sources in both the archive and article. The authors also agree to the non-commercial use of the materials by other researchers or educators, with the stipulation that any publications or presentations that are facilitated by such use will cite both the originating article and the Web materials that were downloaded.

Every effort has been made to ensure that these materials are as complete and accurate as possible, and virus-free, but no warranty or fitness is implied. The information is provided on an "as 


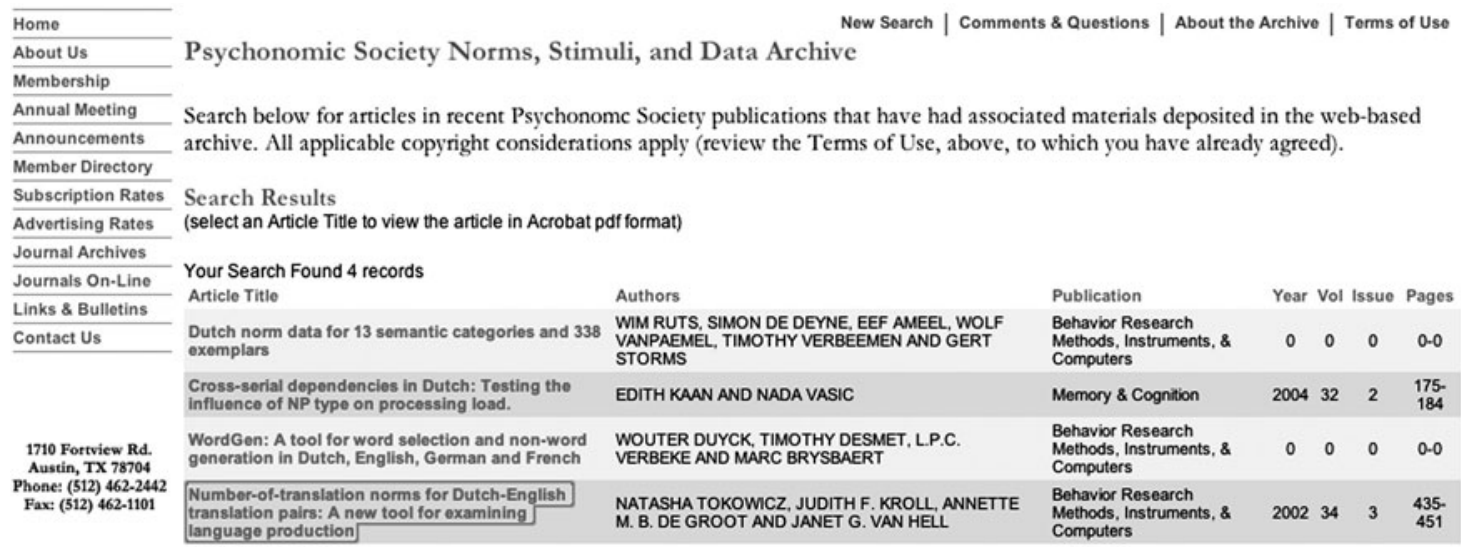

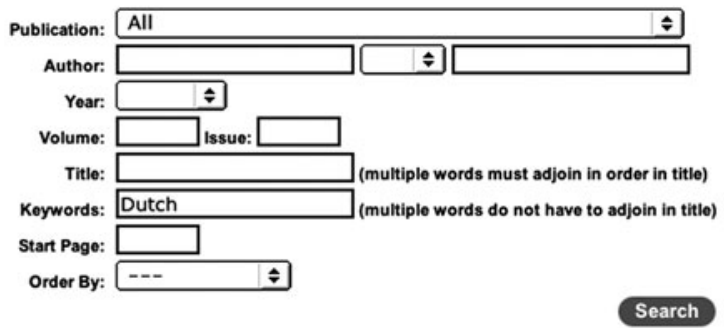

Figure 1. A search at www.psychonomic.org/archive for all entries that contain the keyword Dutch retrieves four entries: Duyck et al. (2004); Kaan and Vasić (2004); Ruts et al. (2004); and Tokowicz et al. (2002).

is" basis. The authors and publisher shall have neither liability or responsibility to any person or entity with respect to any loss or damages arising from the information on this Website or its use.

After agreeing to the terms of use, users may search the archive in a number of ways: by journal, year of publica- tion, author, keyword, and so forth. Figures 1 and 2 present an example of a search by a hypothetical researcher who is interested in studying language in English/Dutch bilinguals, and who is therefore searching for a suitable set of stimulus words (Figures 1 and 2).

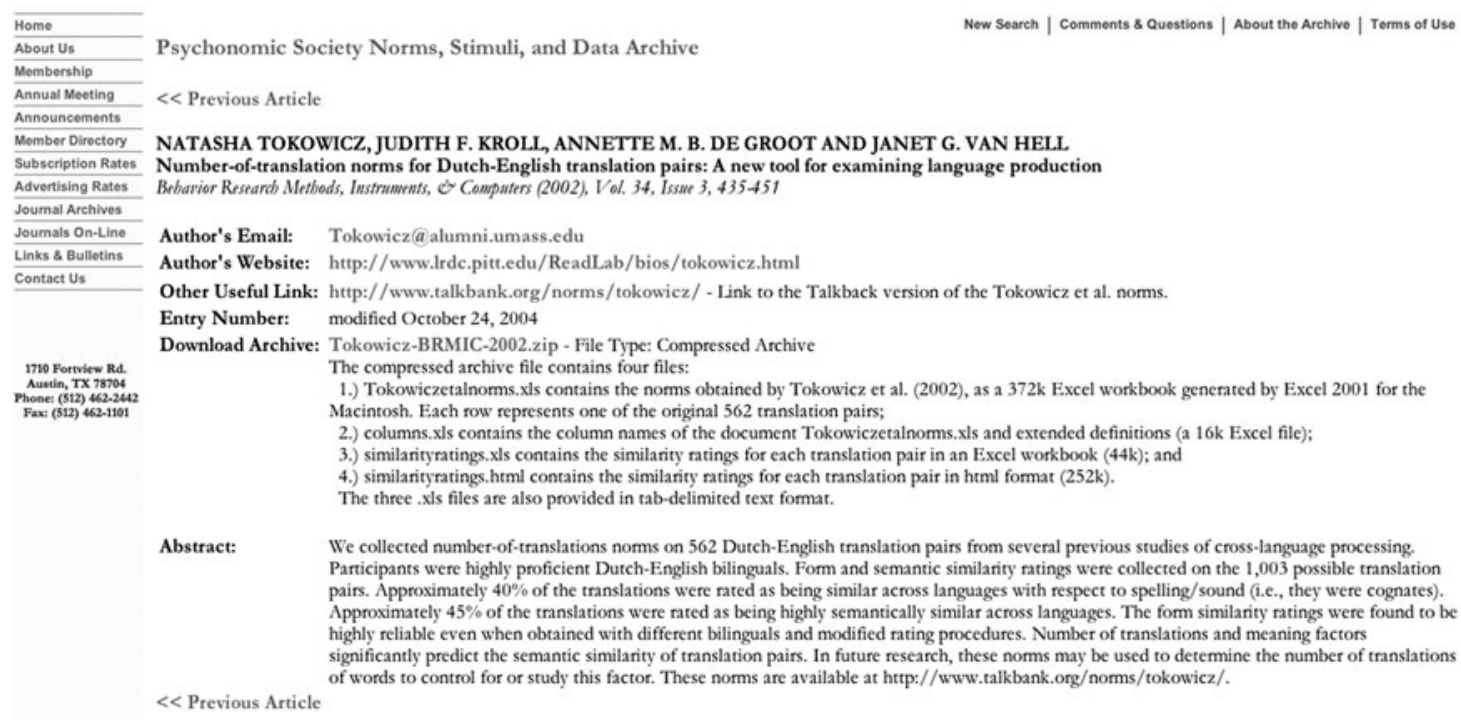

Figure 2. Contents of the Tokowicz et al. (2002) archive entry, which includes Dutch-English and English-Dutch translation norms (downloadable in a .zip-compressed archive file) as well as links to other useful information. 


\section{Contents of the Archive}

Now let us turn to the inaugural contents of the Webbased archive. Initial contributions to the archive have been solicited from three sources. First, entries associated with recently published Psychonomic journal articles (from BRMIC, Learning \& Behavior, Memory \& Cognition, Perception \& Psychophysics, and Psychonomic Bulletin \& Review) are already in the archive. Second, when the Web-based archive was first contemplated, contributions were solicited for a special issue of BRMIC. The enthusiastic response to this initiative is reflected in the number and variety of submissions, which fill both the August and November issues. Third, a number of newer entries in the archive are associated with articles still in press in one of the Psychonomic journals.

The articles in this issue of $B R M I C$ describe more than 40 contributions to the Web-based archive. The contributions fall into four broad categories (with some contributions straddling the arbitrary boundaries): (1) norms for verbal or visual materials that may be used in experiments; (2) stimuli in several modalities (auditory, visual, and textual) and methods for generating them; (3) data from empirical work that can be further explored for analysis, testing of hypotheses, and the evaluation of models; and (4) source code, in a variety of languages, for stimulus generation, statistical analysis, modeling, and experimental control.

The overview that follows is brief. The abstracts of all papers with archived content (including those in press) are in the archive (www.psychonomic.org/archive) and the articles' full text (except for papers still in press) may be found through www.psychonomic.org or in the print journals.

\section{Norms}

Published norms provide important documentation. Psychonomic journals and those of other societies have frequently published extensive tables of norms for verbal and pictorial materials. Proctor and Vu (1999) identified 142 such papers in Psychonomic journals alone, and many others have appeared since the Proctor and Vu index was compiled. The present initiative builds on this tradition. Briefly, the archive now contains the following contributions of normative data.

\section{Norms in English}

Clark and Paivio (2004) extend the Paivio, Yuille, and Madigan (1968) imagery norms from the original corpus of 925 words to 2,511, and provide ratings from a more diverse set of properties for them. Cortese and Fugett (2004), similarly, extend the Toglia and Battig (1978) ratings of 1,153 words to provide imageability ratings for 3,000 monosyllabic words. McRae, Cree, Seidenberg, and McNorgan (in press) provide semantic feature production norms for 541 basic-level concepts.

Jones and Mewhort (2004) provide an extensive corpus of letter and bigram frequency counts based on large samples of unconstrained text. With a more specific emphasis, Novick and Sherman (2004) have focused on bigram distributions in five-letter words. The Novick and Sherman norms are supplemented by the PASCAL source code for their bigram counting program, to facilitate the extension of the work to other computer languages or linguistic samples.

Nelson, McEvoy, and Schreiber (2004) have contributed freeassociation norms for more than 5,000 words, comprising more than
72,000 word pairs, along with a number of related measures. White and Abrams (2004) focus on associations to homophone pairs and triplets with special attention to equivalence across age groups.

Maki et al. (2004) provide a summary of semantic distances in word pairs derived from a corpus of some 50,000 pairs, as well as a pointer to their electronic dictionary/lexical database, WordNet. Gahl, Jurafsky, and Roland (2004) focus on a particular aspect of word meaning, verb subclassification, based on a corpus of 281 verbs.

Crawford, Leynes, Mayhorn, and Bink (2004) make available a sample of 248 words that elicit gender-based associations, along with 352 neutral words, for studies of gender stereotyping and verbal memory. In addition to the norms, the archives provide the raw data on which they are based.

\section{Linguistic Technical Supplements}

Curtiss, MacSwan, Schaeffer, Kural, and Sano (2004) have archived a detailed technical manual describing GCS, their grammatical coding system for research on natural language. Vitevitch and Luce (2004) provide a link to their Web-based resource for the computation of phonotactic probabilities.

\section{Norms in Other Languages}

A number of contributions reflect the strong current interest in comparative studies of language and bilingualism. Reflecting this interest, Duyck, Desmet, Verbeke, and Brysbaert (2004) describe a downloadable tool, WordGen, that generates suitably constrained word and nonword stimulus sets in Dutch, English, German, and French.

Cantonese. Leung, Law, and Fung (2004) report type and token frequencies of tones, onsets, codas, rimes, and syllables from a large corpus of spoken Cantonese.

Dutch. Tokowicz, Kroll, de Groot, and van Hell (2002) have provided translation norms between English and Dutch. Ruts et al. (2004) contribute normative data for categories and superordinates in Dutch. Kaan and Vasić (2004) have archived the sentences used in their study of cross-serial dependencies in Dutch.

French. New, Pallier, Brysbaert, and Ferrand (2004) describe, and provide a link to, their new French lexical database, Lexique. Cordier and Le Ny (in press) archive the stimuli (in French) and dependent measures of their study of the components for word familiarity.

French norms for pictures. Bonin, Peereman, Malardier, Méot, and Chalard (2003) have provided French norms for 299 pictures, while Schwitter, Boyer, Méot, Bonin, and Laganaro (2004) provide normative data on the naming, in French, of 112 drawing of actions.

Italian. Rinaldi, Barca, and Burani (2004) share imageability, frequency and grammatical data for Italian children's first words.

Japanese. In one contribution, Tamaoka and Makioka (2004a) provide frequency information for phonemes, morae, and syllables in a large Japanese corpus. In another, Tamaoka and Makioka (2004b) archive an update of their database of the characteristics of the basic Japanese kanji (Tamaoka, Kirsner, Yanase, Miyaoka, \& Kawakami, 2002).

Japanese norms for pictures. Nishimoto, Miyawaki, Ueda, Une, and Takahashi (in press) archive their norms for selected Snodgrass and Vanderwart (1980) pictures and provide 143 newly drawn stimuli.

Spanish. Izura, Hernández-Muñoz, and Ellis (in press) provide norms for 500 Spanish words in five semantic categories. Dasí, Soler, and Ruiz (2004) share normative data on the completion of Spanish word fragments.

Spanish norms for pictures. Cuetos, Ellis, and Alvarez (1999) have archived their norms for the Snodgrass and Vanderwart (1980) picture set in Spanish, and Cuetos and Alija (2003) provide norms for another 100 pictures. Fernandez, Diez, Alonso, and Beato (2004) provide Spanish free-association norms for the names of Snodgrass and Vanderwart pictures.

Multilanguage norms for pictures. The archive provides links to the multi-language picture-naming norms of Székely et al. (2003) and to the comprehensive and extensive sample of Bates et al. (2003). 


\section{Stimuli}

The archive now contains examples of auditory, visual, and textual stimuli, as well as program source code for generating others.

Auditory stimuli. Saberi (2004) shares an ingenious FFT-based algorithm for generating moving auditory stimuli from monaural waveforms, along with the MatLab source code for implementing it. Shafiro and Gygi (2004) provide access to a wide variety of sources for environmental sounds. Gupta et al. (2004) have archived their stimuli from learning studies: more than 2,500 .wav files of spoken nonsense words of one to seven syllables, and their set of novel visual stimuli: 144 pictures of "space aliens," which vary along several controlled dimensions.

Visual stimuli. DeWinter and Wagemans (2004) share their set of silhouettes and outlines for studies of object identification and segmentation, with parametric variations of contour smoothing. McDougall, Curry, and de Bruijn (1999) have archived rating norms for 239 symbols and icons from a variety of sources. Vanrie and Verfaillie (2004) contribute a set of point-light displays of 22 human movements from different viewpoints, as .avi movie files, along with the numerical description of the points' motions so that they can be adapted for other uses.

Several archive entries already mentioned also provide access to pictures of various kinds (e.g., Bates et al., 2003; Gupta et al., 2004; Nishimoto et al., in press; Székely et al., 2003).

Photographs of faces. Minear and Park (2004) describe a set of photographs of 575 faces, ranging from ages 18 to 93 , suitable for memory and age-related topics. Palermo and Coltheart (2004) provide norms for the ratings of emotions in 335 faces from four source collections. Yoon et al. (2004) provide a corpus of pictures and naming norms, standardized in cross-cultural (American and Chinese) and multiage samples.

Textual stimuli. Marsh (2004) provides nine narrative stories for studies of suggestibility and false memory, as well as a technical description of how to generate such materials.

\section{Data}

The data contributions effectively articulate the utility of data archiving, by demonstrating how archived data can be exploited to address research questions that were not foreseen when the original study was conducted. As Crystal (2004) notes, archiving of data is fully consistent with the expressed goals of the American Psychological Association for the maintenance of data for a reasonable period after original publication, and it is particularly valuable in the domain of animal research because of the cost and difficulty of generating the original data.

Boker and Crowell (2004) summarize the arguments for data archiving, using GenBank as an example that particular disciplines might profitably emulate ${ }^{2}$.

Research using animals. Crystal (2004) demonstrates the utility of archived data in the reanalysis of timing performance by a chimpanzee in orbit, using data from the NASA electronic archive. Guilhardi and Church (2004) report a study of rats' timing behavior, and set the admirable precedent of archiving their raw data (the individual responses of 12 rats across 10 sessions each) for the use of other researchers who may wish to apply different models of analysis to them. They also provide the MatLab source code of a program with which the data may be further explored.

Research using humans. Heathcote (2004) provides a combination of data and program resources that other modelers will find especially useful in downloadable form. He models the RT distribution of empirical data generously provided by Schwarz (2001), and archives the S-PLUS functions used to test Schwarz's data against the Ex-Wald distribution. Schwarz's raw data are also provided, for the benefit of other potential modelers. Schooler and Schiffrin (in press) archive the data produced in the comparison of different signal-detection models applied to sparse data sets. Macmillan, Rotello, and Miller (2004) provide a link to their reports of the accuracy and precision for measures of sensitivity and variance in signaldetection analysis.

\section{Source Code}

Sharing computer source code serves many purposes. Source code for data analysis may be adopted by other researchers, to perform the same analysis on different data, for example. Source code may be adapted by other researchers to perform new, but related analyses. Source code is didactic, to the benefit of researchers or students who may wish to understand the underlying logic, to implement the same algorithm on another platform, or to generalize the application to new areas. Archiving of source code facilitates accountability, in that other researchers can verify that the code is correct - or detect bugs in it. ${ }^{3}$

Many useful algorithms can be implemented on more than one computing platform, or in more than one proprietary syntax (SPSS and SAS, for example; or MatLab and FORTRAN). Contributors are encouraged to provide source code for more than one computer language, to maximize its utility. Doing so also helps to ensure the implementation's accuracy by demonstrating that it works in more than one independent implementation. Several of the above entries include contributions of source code along with other materials, and there are other contributions of source code alone.

Statistics and modeling. Dunlap, Xin, and Myers (2004) provide the FORTRAN source code for computing the power of multiple regression analyses, as well as links to other statistical resources. Tuerlinckx (2004) provides FORTRAN and MatLab source code for computing the cumulative distribution function for the diffusion model of RT. As part of their discussion of using maximum likelihood methods in model evaluation, Cousineau, Brown, and Heathcote (2004) include FORTRAN source code for generating sampling distributions of a variety of distributions: Ex-Gaussian, Gumbel, Log-Normal, Wald and Weibull.

DeCarlo (2003) provides SPSS source code for fitting signal detection models. Preacher and Hayes (2004) have archived SPSS and SAS macros for estimating indirect effects in simple mediation models. Wolff and Preising (in press) provide SPSS and SAS syntax code for exploring up to three-level factor structures using the Schmid-Leiman solution

Bogacz and Cohen (2004) provide MatLab source code for a general routine for parameter fitting, by minimizing the difference between statistics based on model output and observed data. Walker and Milne (in press) archive their MatLab source code for exploring function estimators as an alternative to regression.

Experiment control. De Clercq, Crombez, Buysse, and Roeyers (2003) describe a method for verifying timing accuracy, and a link to downloadable software. Collin and McMullen (2002) provide MatLab source code for the generation of families of Attneave shapes.

Eye tracking. Collin and Chaudhuri (2002) offer MatLab source code for generating heterochromatic stimuli for the study of movement perception. Gitelman (2002) provides MatLab source code for offline analysis of eye movement records, and Hornof and Halverson (2002) provide source code for calibration of eye tracking record- 
ing, and Barabas et al. (2004) provide MatLab routines for computing the line of primary gaze in ambulatory eye-tracking studies.

Data acquisition. Abrams and Jennings (2004) have archived Visual Basic source code for a computerized voice key. Duley, Janelle, and Coombes (2004) share a LabVIEW toolkit for phasic heart-rate analysis. Corkrey and Parkinson (2004) provide software and scripts for conducting standardized computer-assisted telephone interviews. Shebilske et al. (in press) have archived an extensive technical manual for their Space Fortress experimental environment.

\section{The Future of the Archive}

Now that the archive has been launched, where do we go from here? In addition to contributions associated with these two issues of BRMIC, the Web-based archive will accept contributions related to previously published papers in BRMIC and other Psychonomic journals, as well as materials associated with future articles accepted in any of the Psychonomic journals. Both authors and editors are encouraged to take the initiative in proposing additions to the archive. Queries about new submissions to the archive, or submissions related to previously published articles, should be addressed to the editor of the relevant Psychonomic journal (see www.psychonomic.org). Other questions about the archive may be directed to Jonathan Vaughan at psp-archive@hamilton.edu or by clicking the "Comments and Questions" button on the Web page.

It goes without saying that additional contributions to the Web archive, in the form of norms, stimuli, data, or program source code, will be welcome. The resource belongs to the community of experimental psychologists, and I look forward to seeing the archive effectively exploited in the service of research and education in experimental psychology.

\section{REFERENCES}

Abrams, L., \& Jennings, D. T. (2004). VoiceRelay: Voice key operation using Visual Basic. Behavior Research Methods, Instruments, \& Computers, 36, 771-777.

Barabas, J., Goldstein, R. B., Apfelbaum, H., Woods, R. L., Giorgi, R. G., \& Peli, E. (2004). Tracking the line of primary gaze in a walking simulator: Modeling and calibration. Behavior Research Methods, Instruments, \& Computers, 36, 757-770.

Bates, E., D’Amico, S., Jacobsen, T., Székely, A., Andonova, E., Devescovi, A., Herron, D., Lu, C. C., Pechmann, T., Pléh, C., Wicha, N., Federmeier, K., Gerditikova, I., Guiterrez, G., Hung, D., Hsu, J., IYer, G., Kohnert, K., Mehotcheva, T., OrozcoFigueroa, A., Tzeng, A., \& Tzeng, O. (2003). Timed picture naming in seven languages. Psychonomic Bulletin \& Review, 10, 344-380.

Bogacz, R., \& CoHEN, J. D. (2004). Parameterization of connectionist models. Behavior Research Methods, Instruments, \& Computers, 36, 732-741.

BoKer, S. M., \& Crowell, C. R. (2004). Proposal for the creation of a Web-based heterogeneous distributed archive for psychological data. Behavior Research Methods, Instruments, \& Computers, 36, 670-677.

Bonin, P., Peereman, R., Malardier, N., Méot, A., \& Chalard, M (2003). A new set of 299 pictures for psycholinguistic studies: French norms for name agreement, image agreement, conceptual familiarity, visual complexity, image variability, age of acquisition, and naming latencies. Behavior Research Methods, Instruments, \& Computers, 35, 158-167.

Clark, J. M., \& Paivio, A. (2004). Extensions of the Paivio, Yuille, and Madigan (1968) norms. Behavior Research Methods, Instruments, \& Computers, 36, 371-383.
Collin, C. A., \& Chaudhuri, A. (2002). Using MATLAB with the Psychophysics Toolbox to present the heterochromatic fusion nystagmus stimulus. Behavior Research Methods, Instruments, \& Computers, 34, 500-508.

Collin, C. A., \& McMullen, P. A. (2002). Using Matlab to generate families of similar Attneave shapes. Behavior Research Methods, Instruments, \& Computers, 34, 55-68.

CoRDIER, F., \& LE NY, J.-F. (in press). Evidence of several components of word familiarity. Behavior Research Methods, Instruments, \& Computers.

Corkrey, R., \& PARKInson, L. (2004). Generalized Electronic Interviewing System (GEIS): A program and scripting method for conducting interviews in multiple modes. Behavior Research Methods, Instruments, \& Computers, 36, 784-796.

Cortese, M. J., \& FugeTt, A. (2004). Imageability ratings for 3,000 monosyllabic words. Behavior Research Methods, Instruments, \& Computers, 36, 384-387.

Cousineau, D., Brown, S., \& Heathcote, A. (2004). Fitting distributions using maximum likelihood: Methods and packages. Behavior Research Methods, Instruments, \& Computers, 36, 742-756.

Crawford, J. T., Leynes, P. A., Mayhorn, C. B., \& Bink, M. L. (2004). Champagne, beer, or coffee? A corpus of gender-related and neutral words. Behavior Research Methods, Instruments, \& Computers, 36, 444-458.

CRYSTAL, J. D. (2004). Data archiving in animal experimentation: Merits, challenges, and a case study. Behavior Research Methods, Instruments, \& Computers, 36, 656-660.

Cuetos, F., \& AliJA, M. (2003). Normative data and naming times for action pictures. Behavior Research Methods, Instruments, \& Computers, 35, 168-177.

Cuetos, F., Ellis, A. W., \& Alvarez, B. (1999). Naming times for the Snodgrass and Vanderwart pictures in Spanish. Behavior Research Methods, Instruments, \& Computers, 31, 650-658.

Curtiss, S., MacSwan, J., Schaeffer, J., Kural, M., \& Sano, T. (2004). GCS: A grammatical coding system for natural language data Behavior Research Methods, Instruments, \& Computers, 36, 459-480.

Dasí, C., Soler, M. J., \& RuIZ, J. C. (2004). Normative data on the familiarity and difficulty of 196 Spanish word fragments. Behavior Research Methods, Instruments, \& Computers, 36, 559-563.

DeCarlo, L. T. (2003). Using the PLUM procedure of SPSS to fit unequal variance and generalized signal detection models. Behavior Research Methods, Instruments, \& Computers, 35, 49-56.

De ClercQ, A., Crombez, G., Buysse, A., \& Roeyers, H. (2003). A simple and sensitive method to measure timing accuracy. Behavior Research Methods, Instruments, \& Computers, 35, 109-115.

De Winter, J., \& Wagemans, J. (2004). Contour-based object identification and segmentation: Stimuli, norms and data, and software tools. Behavior Research Methods, Instruments, \& Computers, 36, 604-624.

Duley, A. R., Janelle, C. M., \& Coombes, S. A. (2004). An opensource LabVIEW application toolkit for phasic heart rate analysis in psychophysiological research. Behavior Research Methods, Instruments, \& Computers, 36, 778-783.

DunlaP, W. P., XIN, X., \& Myers, L. (2004). Computing aspects of power for multiple regression. Behavior Research Methods, Instruments, \& Computers, 36, 695-701.

Duyck, W., Desmet, T., Verbeke, L. P. C., \& Brysbaert, M. (2004). WordGen: A tool for word selection and nonword generation in Dutch, English, German, and French. Behavior Research Methods, Instruments, \& Computers, 36, 488-499.

Fernandez, A., Diez, E., Alonso, M. A., \& Beato, M. S. (2004). Free-association norms for the Spanish names of the Snodgrass and Vanderwart pictures. Behavior Research Methods, Instruments, \& Computers, 36, 577-583.

Gahl, S., JURAFSKY, D., \& Roland, D. (2004).Verb subcategorization frequencies: American English corpus data, methodological studies, and cross-corpus comparisons. Behavior Research Methods, Instruments, \& Computers, 36, 432-443.

Gitelman, D. R. (2002). ILAB: A program for postexperimental eye movement analysis. Behavior Research Methods, Instruments, \& Computers, 34, 605-612. 
Guilhardi, P., \& Church, R. M. (2004). Measures of temporal discrimination in fixed-interval performance: A case study in archiving data. Behavior Research Methods, Instruments, \& Computers, 36, 661-669.

Gupta, P., Lipinski, J., AbBs, B., Lin, P.-H., Aktunc, E., Ludden, D., Martin, N., \& Newman, R. (2004). Space aliens and nonwords: Stimuli for investigating the learning of novel word-meaning pairs. Behavior Research Methods, Instruments, \& Computers, 36, 599-603.

HeAtнсоте, A. (2004). Fitting Wald and ex-Wald distributions to response time data: An example using functions for the S-PLUS package. Behavior Research Methods, Instruments, \& Computers, 36, 678694.

Hornof, A. J., \& Halverson, T. (2002). Cleaning up systematic error in eye-tracking data by using required fixation locations. Behavior Research Methods, Instruments, \& Computers, 34, 592-604.

Izura, C., Hernández-Muñoz, N., \& Ellis, A. W. (in press). Category norms for 500 Spanish words in five semantic categories. Behavior Research Methods, Instruments, \& Computers.

Jones, M. N., \& MewhorT, D. J. K. (2004). Case-sensitive letter and bigram frequency counts from large-scale English corpora. Behavior Research Methods, Instruments, \& Computers, 36, 388-396.

KAAN, E., \& VASIć, N. (2004). Cross-serial dependencies in Dutch: Testing the influence of NP type on processing load. Memory \& Cognition, 32, 175-184.

KirkPatrick, K., \& Church, R. M. (2003). Tracking of the expected time to reinforcement in temporal conditioning procedures. Learning \& Behavior, 31, 3-21.

Kurtzman, H. S., Church, R. M., \& Crystal, J. D. (2002). Data archiving for animal cognition research: Report of an NIMH workshop. Animal Learning \& Behavior, 30, 405-412.

Leung, M.-T., Law, S.-P., \& Fung, S.-Y. (2004). Type and token frequencies of phonological units in Hong Kong Cantonese. Behavior Research Methods, Instruments, \& Computers, 36, 500-505.

Macmillan, N. A., Rotello, C. M., \& Miller, J. O. (2004). The sampling distributions of Gaussian ROC statistics. Perception \& Psychophysics, 66, 406-421.

Maki, W. S., McKinley, L. N., \& Thompson, A. G. (2004). Semantic distance norms computed from an electronic dictionary (WordNet) Behavior Research Methods, Instruments, \& Computers, 36, 421-431.

MARSH, E. J. (2004). Story stimuli for creating false beliefs about the world. Behavior Research Methods, Instruments, \& Computers, $\mathbf{3 6}$ 650-655.

McDougall, S. J. P., Curry, M. B., \& DE Bruijn, O. (1999). Measuring symbol and icon characteristics: Norms for concreteness, complexity, meaningfulness, familiarity, and semantic distance for 239 symbols. Behavior Research Methods, Instruments, \& Computers, 31, 487-519.

McRae, K., Cree, G. S., Seidenberg, M. S., \& McNorgan, C. (in press). Semantic feature production norms for a large set of living and nonliving things. Behavior Research Methods, Instruments, \& Computers.

Minear, M., \& PARK, D. C. (2004). A lifespan database of adult facial stimuli. Behavior Research Methods, Instruments, \& Computers, 36 630-633.

Nelson, D. L., McEvoy, C. L., \& Schreiber, T. A. (2004). The University of South Florida free association, rhyme, and word fragment norms. Behavior Research Methods, Instruments, \& Computers, 36, 402-407.

New, B., Pallier, C., Brysbaert, M., \& Ferrand, L. (2004). Lexique 2: A new French lexical database. Behavior Research Methods, Instruments, \& Computers, 36, 516-524.

Nishimoto, T., Miyawaki, K., Ueda, T., Une, Y., \& TaKahashi, M. (in press). Japanese normative set of 359 pictures. Behavior Research Methods, Instruments, \& Computers.

Novick, L. R., \& Sherman, S. J. (2004). Type-based bigram frequencies for five-letter words. Behavior Research Methods, Instruments, \& Computers, 36, 397-401.

Paivio, A., Yuille, J. C., \& Madigan, S. A. (1968). Concreteness, imagery, and meaningfulness values for 925 nouns. Journal of Experimental Psychology, 76 (1, Pt. 2), 1-25.

Palermo, R., \& Coltheart, M. (2004). Photographs of facial expression: Accuracy, response times, and ratings of intensity. Behavior Research Methods, Instruments, \& Computers, 36, 634-638.
Preacher, K. J., \& Hayes, A. F. (2004). SPSS and SAS procedures for estimating indirect effects in simple mediation models. Behavior Research Methods, Instruments, \& Computers, 36, 717-731.

Proctor, R. W., \& VU, K.-P. L. (1999). Index of norms and ratings published in the Psychonomic Society journals. Behavior Research Methods, Instruments, \& Computers, 31, 659-667.

RinALDI, P., BARCA, L., \& Burani, C. (2004). A database for semantic, grammatical, and frequency properties of the first words acquired by Italian children. Behavior Research Methods, Instruments, \& Computers, 36, 525-530.

Ruts, W., De Deyne, S., Ameel, E., Vanpaemel, W., Verbeemen, T., \& STORMs, G. (2004). Dutch norm data for 13 semantic categories and 338 exemplars. Behavior Research Methods, Instruments, \& Computers, 36, 506-515.

SABERI, K. (2004). Fast Fourier-based DSP algorithm for auditory motion experiments. Behavior Research Methods, Instruments, \& Computers, 36, 585-589.

SCHOOLER, L. J., \& SCHIFFrin, R. M. (in press). Efficiently measuring recognition performance with sparse data. Behavior Research Methods, Instruments, \& Computers.

Schwarz, W. (2001). The ex-Wald distribution as a descriptive model of response times. Behavior Research Methods, Instruments, \& Computers, 33, 457-469.

Schwitter, V., Boyer, B., Méot, A., Bonin, P., \& Laganaro, M. (2004). French normative data and naming times for action pictures. Behavior Research Methods, Instruments, \& Computers, 36, 564-576.

Shafiro, V., \& GYGI, B. (2004). How to select stimuli for environmental sound research and where to find them? Behavior Research Methods, Instruments, \& Computers, 36, 590-598.

Shebilske, W. L., Volz, R. A., Gildea, K. M., Workman, J. W., NanJanath, M., CaO, S., \& Whetzel, J. (in press). Revised Space Fortress: A validation study. Behavior Research Methods, Instruments, \& Computers.

SnOdGrass, J. G., \& VANDERWART, M. (1980). A standardized set of 260 pictures: Norms for name agreement, image agreement, familiarity, and visual complexity. Journal of Experimental Psychology: Human Learning \& Memory, 6, 174-215.

Székely, A., D’Amico, S., Devescovi, A., Federmeier, K., Herron, D., IYeR, G., JACOBSON, T., \& BATES, E. (2003). Timed picture naming: Extended norms and validation against previous studies. Behavior Research Methods, Instruments, \& Computers, 35, 621-633.

Tamaoka, K., Kirsner, K, Yanase, Y., MiyaOKa, Y., \& Kawakami, M. (2002). A Web-accessible database of characteristics of the 1,945 basic Japanese Kanji. Behavior Research Methods, Instruments, \& Computers, 34, 260-275.

TAMAOKA, K., \& MAKIOKA, S. (2004a). Frequency of occurrence for units of phonemes, morae, and syllables appearing in a lexical corpus of a Japanese newspaper. Behavior Research Methods, Instruments, \& Computers, 36, 531-547.

TAMAOKA, K., \& MAKIOKA, S. (2004b). New figures for a Web-accessible database of the 1,945 basic Japanese kanji, fourth edition. Behavior Research Methods, Instruments, \& Computers, 36, 548-558.

Toglia, M. P., \& Battig, W. F. (1978). Handbook of semantic word norms. Hillsdale, NJ: Erlbaum.

Tokowicz, N., Kroll, J. F., de Groot, A. M. B., \& van Hell, J. G. (2002). Number-of-translation norms for Dutch-English translation pairs: A new tool for examining language production. Behavior Research Methods, Instruments, \& Computers, 34, 435-451.

Tuerlinckx, F. (2004). The efficient computation of the cumulative distribution and probability density functions in the diffusion model. Behavior Research Methods, Instruments, \& Computers, 36, 702-716.

VanRie, J., \& Verfaillie, K. (2004). Perception of biological motion: A stimulus set of human point-light actions. Behavior Research Methods, Instruments, \& Computers, 36, 625-629.

Vitevitch, M. S., \& Luce, P. A. (2004). A Web-based interface to calculate phonotactic probability for words and nonwords in English. Behavior Research Methods, Instruments, \& Computers, 36, 481-487.

WALKER, I., \& MiLNE, S. (in press). Exploring function estimators as an alternative to regression in psychology. Behavior Research Methods, Instruments, \& Computers.

White, K. K., \& Abrams, L. (2004). Free associations and dominance 
ratings of homophones for young and older adults. Behavior Research Methods, Instruments, \& Computers, 36, 408-420.

WolfF, H.-G., \& Preising, K. (in press). Exploring item and higher order factor structure with the Schmid-Leiman solution: Syntax codes for SPSS and SAS. Behavior Research Methods, Instruments, \& Computers.

Yoon, C., Feinberg, F., Luo, T., Hedden, T., Gutchess, A. H., Chen, H.-Y. M., Mikels, J. A., Jiao, S., \& Park, D. C. (2004). A crossculturally standardized set of pictures for younger and older adults: American and Chinese norms for name agreement, concept agreement, and familiarity. Behavior Research Methods, Instruments, \& Computers, 36, 639-649.

\section{NOTES}

1. "Print" is shorthand for the conventional article in a scholarly journal, which may, of course, be widely (and sometimes exclusively) disseminated electronically.

2. Boker and Crowell (2004) propose an ingenious method for generating a "virtual," self-organizing archive of reports and data, imple- mented by having researchers include a keyword, PsychologicalDataArchive on the Web page of each self-published contribution. In this way, a suitably qualified Google search would reveal the self-archived contents that are germane to a particular topic. In the case of the Psychonomic Web-based archive, a similar search strategy can be implemented using PsycINFO or Web of Science. Searching for the text www.psychonomic.org/archive in the abstract field of the database will retrieve the entries for articles published with an archive supplement (though it will not detect entries submitted to supplement previously published articles).

3. As a matter of policy, computer programs in the archive are limited to text-based source code, for several reasons. Properly documented source text is easily interpreted and verified, and it cannot be infected with a virus or a Trojan program. Source code is useful even if the operating system or proprietary software for which it was designed is not accessible or no longer supported, because the logic of the program can be deduced from the code. Authors may, of course, make executable code available on their own Websites, though prudent users will always download executable programs cautiously, only from fully trusted sites, and always at their own risk. 